\title{
ERRATUM
}

\section{CORRECTION TO "LASER INDUCED LINE NARROWING AND SATURATION BROADENING EFFECTS IN OPFIRL"}

\section{Lin Yikun and Luo Xizhang}

Received June 1, 1991

In the paper ${ }^{1}$ some errors should be corrected.

The linewidth of the gain factor of homogeneous broadening system was proportional to the operating gas pressure:

$$
\Delta f_{L}=130 * P / \pi(9.09 \mathrm{E}-7) \quad\left(\text { For } \mathrm{HH}_{3} \text { gas) }{ }^{[2]}\right.
$$

1 Lin Yikun and Luo Xizhang, International J. IR and MM Waves Vol. 11, No. 4, p 565, 1990. 